\title{
Ventricular arrhythmias in idiopathic dilated cardiomyopathy
}

\author{
K VON OLSHAUSEN, A SCHÄFER, H C MEHMEL, F SCHWARZ, J SENGES, W KÜBLER
}

From the University Medical Clinic, Department of Internal Medicine III (Cardiology), Heidelberg, West Germany

SUMmaRY Twenty four hour ambulatory electrocardiograms were recorded in 60 patients with idiopathic dilated cardiomyopathy. The diagnosis was based on clinical, laboratory, and cardiac catheterisation findings. All patients had a left ventricular ejection fraction $<0.55$; in 39 it was $<0.40$. Ventricular extrasystoles were evident in all patients: they were rare in $11(18 \%)$, moderately frequent in $24(40 \%)$, and frequent in $25(42 \%)$. Multiform extrasystoles were recorded in 57 patients (95\%), paired ventricular extrasystoles in $47(78 \%)$, and non-sustained ventricular tachycardias consisting of three to 19 beats in $25(42 \%)$ of the 60 patients studied. Eight patients had more than five episodes of ventricular tachycardia a day. Patients with atrial fibrillation had the same frequency and grade of ventricular arrhythmias as those with sinus rhythm. Patients with infrequent and frequent ventricular extrasystoles could not be differentiated on the basis of the clinical or haemodynamic findings. The mean values of NYHA functional class, cardiac index, left ventricular end diastolic pressure, and ejection fraction were, however, significantly different in patients with and without ventricular tachycardia. During follow up of $12 \pm 5$ months seven patients died; all seven had an ejection fraction $<0.40$. In four patients who died of congestive heart failure, but in only one of the three patients who died a sudden cardiac death, ventricular tachycardia was recorded during ambulatory monitoring.

High grade ventricular arrhythmias are often seen in patients with idiopathic dilated cardiomyopathy; patients with ventricular tachycardia have more impairment of left ventricular function than patients without ventricular tachycardia; and ambulatory monitoring may be of little help in identifying patients at increased risk of sudden cardiac death.

The incidence of sudden and unexpected cardiac death in patients with idiopathic dilated cardiomyopathy is estimated to be between 20 and $45 \% .{ }^{12}$ In contrast to hypertrophic cardiomyopathy, of which several systematic studies have shown a high prevalence of repetitive ventricular extrasystoles ${ }^{3}{ }^{4}$-which may presage sudden cardiac death-only two recent studies of ventricular arrhythmias using ambulatory electrocardiography have been carried out in patients with idiopathic dilated cardiomyopathy. ${ }^{5}$ We have, therefore, evaluated the data on 60 patients with idiopathic dilated cardiomyopathy who were receiving no antiarrhythmic treatment in a prospective study.

Requests for reprints to $\mathrm{Dr} \mathrm{K}$ von Olshausen, Innere Medizin III, Bergheimer Strasse 58, D-6900 Heidelberg, West Germany.

Accepted for publication 30 August 1983
Twenty four hour ambulatory electrocardiograms were used to determine the prevalence, frequency, and characteristics of ventricular arrhythmias. Furthermore, we assessed whether or not the clinical or haemodynamic features were predictive of complex ventricular arrhythmias.

\section{Patients and methods}

STUDY POPULATION

Between July 1981 and December 1982, 102 consecutive patients with an initial diagnosis of cardiomyopathy were studied by right and left heart catheterisation. Patients were included in the study if the following criteria were fulfilled ${ }^{278}:(a)$ the presence of symptoms or signs of left or right heart failure, or both; $(b)$ roentgenographic evidence of cardiomegaly - that is, a cardiothoracic ratio $>0.50$; (c) a dilated left ventricle with a reduced ejection 
fraction $(\leqslant 0.55) ;(d)$ an absence of coronary heart disease (confirmed by selective coronary angiography); $(e)$ an absence of valve lesions except for mild or moderate mitral regurgitation; $(f)$ a normal serum potassium concentration $(3.5-5.0 \mathrm{mmol}(\mathrm{mEq}) / \mathrm{l})$ on the day of ambulatory monitoring ( \pm 24 hours); $(g)$ no treatment with a specific antiarrhythmic agent two weeks before the day of ambulatory monitoring (patients taking digoxin or diuretics were included in the study); and ( $h$ ) an absence of specific heart muscle disease, general systemic disease, heredofamilial disorders, systemic hypertension, or cor pulmonale.

Using these criteria 60 patients (54 men, six women; mean age $45 \pm 9$ (range 18-60) years) were selected for study; 49 patients were taking digoxin and 38 diuretics.

\section{CLINICAL EVALUATION}

The symptomatic status of all patients was classified according to the criteria of the New York Heart Association. ${ }^{9}$ During admission 12 lead electrocardiograms were recorded. They were interpreted by two independent observers. Follow up information was obtained by telephone calls to the family doctor or by reviewing the outpatient files.

\section{ECHOCARDIOGRAPHY AND CARDIAC CATHETERISATION}

All patients were studied by $M$ mode and cross sectional echocardiography (Picker Echoview 80C) to detect any heart disease that might exclude the patient from the study. Right and left heart catheterisation including selective coronary angiography (Judkins's technique) was performed in all patients. Biplane $35 \mathrm{~mm}$ cineangiograms of the left ventricle were filmed (40-50 ml Urografin 76, 50 frames per second, $30^{\circ}$ right anterior oblique and $45^{\circ}$ left anterior oblique projections). Left ventricular volume and left ventricular ejection fraction were calculated using the computer aided area-length method (MennenGreatbatch system). Mild mitral regurgitation was found in 11 patients and moderate regurgitation in four. Cardiac index was determined according to the Fick principle.

\section{AMBULATORY ELECTROCARDIOGRAPHIC MONITORING}

During the 48 hours before or after cardiac catheterisation ambulatory electrocardiographic monitoring (mean duration 24 (range 19-26) hours) was performed. The ambulatory electrocardiogram was recorded on a one channel Oxford Medilog Mark I recorder using a bipolar V1-V5 lead system. All recordings were analysed twice semiautomatically using the Reynolds Pathfinder system and a Digital PDP 11/03 computer. ${ }^{10}$ During automatic analysis all tapes were simultaneously scanned visually on the oscilloscope by an experienced technician. When an arrhythmia was suspected that portion of the tape was printed out. Examples of all types of ventricular extrasystoles, all paired ventricular extrasystoles, and all ventricular tachycardias were printed on paper and interpreted by a cardiologist. In each patient the number of episodes of ventricular tachycardia per 24 hours, the number of beats per episode, the rate of ventricular tachycardia, and the prematurity index of the initiating beat of each episode were analysed.

A modified Lown grading system as described by Ryan et al for ventricular arrhythmias ${ }^{11}$ was used: grade 0 , no ventricular extrasystoles in 24 hours; grade 1 , occasional ventricular extrasystoles but no more than 30 in any hour of monitoring; grade 2, more than 30 ventricular extrasystoles in any hour of monitoring; grade 3, multiform ventricular extrasystoles; grade 4a, couplets (two consecutive ventricular extrasystoles); grade $4 \mathrm{~b}$, ventricular tachycardia (three or more ventricular extrasystoles in succession with a rate $>100 / \mathrm{min}$ ).

\section{STATISTICAL ANALYSIS}

Data are expressed as mean values \pm standard deviation. Where appropriate the $t$ test for unpaired data, the $\chi^{2}$ correlation test, Fisher's exact test, and the $\mathrm{U}$ test for rank correlation (Kendall's method) were used to assess statistical significance. ${ }^{12}$ With the two tail test a probability value $<0.05$ was considered to be significant. The correlations between ventricular arrhythmias (incidence of ventricular extrasystoles and grade of arrhythmia) were calculated using Spearman's rank correlation coefficient $\left(r_{s}\right)$ with Kendall's modification. ${ }^{12}$

\section{Results}

CLINICAL AND HAEMODYNAMIC FINDINGS

Thirty four of the $60(57 \%)$ patients were in NYHA functional class III, $16(27 \%)$ in class II, and $10(17 \%)$ in class IV. The mean period between initial clinical manifestation and entry into the study was $2.9 \pm 2.5$ years. The mean left ventricular ejection fraction was $0.35 \pm 0.11$ (range $0.09-0.55$ ). Thirty nine patients had an ejection fraction $<0.40$. The mean left ventricular end diastolic pressure was $17 \pm 8 \mathrm{~mm} \mathrm{Hg}$ (range $5-36$ $\mathrm{mm} \mathrm{Hg}$ ). The mean cardiac index was $2.5 \pm 0.71 /$ $\mathrm{min} / \mathrm{m}^{2}$.

The electrocardiogram at rest showed atrial fibrillation in $11(18 \%)$ patients, left bundle branch block in $18(30 \%)$, left axis deviation in four (7\%), intraventricular conduction delay in two (3\%), and first degree atrioventricular block in two (3\%). 


\section{ELECTROCARDIOGRAPHY}

\section{Ventricular arrhythmias}

All patients had ventricular extrasystoles (range 1-20219 (mean 2505 \pm 4437 ) per 24 hours). Ventricular extrasystoles were rare $(<100 / 24 \mathrm{~h})$ in 11 patients $(18 \%)$, moderately frequent $(101-1000 / 24 \mathrm{~h})$ in 24 $(40 \%)$, and frequent $(>1000 / 24 \mathrm{~h})$ in $25(42 \%)$. The maximum number of ventricular extrasystoles in any one hour was $251 \pm 399$. There was an excellent correlation between the maximum number of ventricular extrasystoles/hour and the total number $/ 24 \mathrm{~h}$ $\left(r_{s}=0.97, p<0.001\right)$.

Table 1 summarises the classification of ventricular arrhythmias by maximum and cumulative grades according to the classification of Ryan et al. ${ }^{11}$ High grade ventricular arrhythmias (grade 3 and higher) occurred in $57(95 \%)$ patients, and repetitive ventricular extrasystoles (grade $4 a$ and $4 b$ ) in $48(80 \%)$. Twenty five patients had ventricular tachycardias. If a patient had $>30$ ventricular extrasystoles in any one hour, a higher grade of ventricular arrhythmia (grade 3 or higher) was also present. There was a moderate correlation between the number of ventricular extrasystoles and the grade of arrhythmia $\left(r_{s}=0.52\right.$, $\mathrm{p}<0.001$; Fig. 1).

\section{Ventricular tachycardia}

A total of 247 episodes of ventricular tachycardia was recorded in 25 patients (median 1.5 (range 1-105) episodes/patient). All episodes were brief (3-19 beats) and were not noticed by the patient. The heart rate within the ventricular tachycardias ranged from 105 to 210 beats $/ \mathrm{min}$ (mean $144 \pm 32$ beats $/ \mathrm{min}$ ). No significant correlation was found between the sinus rate just before ventricular tachycardia and the rate of ventricular tachycardia $\left(r_{s}=-0.11, N S\right)$. Only three $(1 \%)$ episodes were initiated by a $\mathrm{R}$ on $\mathrm{T}$ phenomenon. Fig. 2 shows further characteristics of the episodes of ventricular tachycardia.

\section{Atrial fibrillation}

Since runs with aberrant conduction might have been classified as ventricular tachycardia in the presence of

Table 1 Grade of ventricular extrasystoles during 24 hour ambulatory electrocardiographic monitoring. Figures are numbers (\%) of patients

\begin{tabular}{llllllll}
\hline \multicolumn{6}{c}{ Grade of arrhythmias } \\
\cline { 2 - 7 } & 0 & 1 & 2 & 3 & $4 a$ & $4 b$ \\
\hline Maximum grade & $0(0)$ & $3(5)$ & $0(0)$ & $9(15)$ & $23(38)$ & $25(42)$ \\
Cumulative grade & $0(0)$ & $17(28)$ & $43(72)$ & $57(95)$ & $47(78)$ & $25(42)$ \\
\hline * Not mutually exclusive.
\end{tabular}

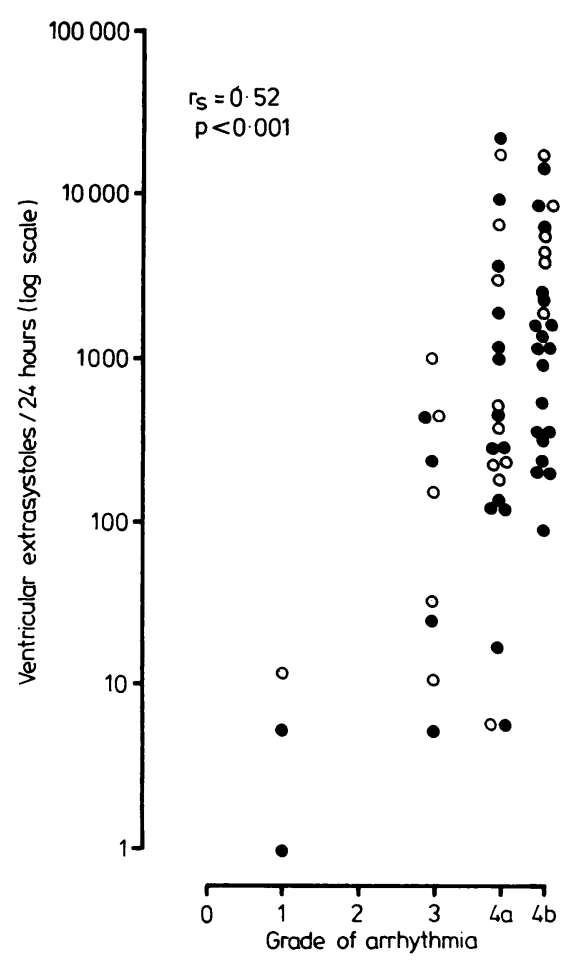

Fig. 1 Relation between the maximum grade of arrhythmia and frequency of ventricular extrasystoles (logarithmic scale). All patients who had $>30$ ventricular extrasystoles in any one hour (arrhythmia grade 2) also had higher grades of arrhythmia (grade $3-4 b)$. (0) high (0.41-0.55) and (0)-low (<0.40) left ventricular ejection fraction.

atrial fibrillation, ${ }^{13}$ we analysed whether or not patients with atrial fibrillation had a greater proportion of ventricular extrasystoles or ventricular tachycardias compared with the rest of the study group (Table 2).

The 11 patients with atrial fibrillation had a lower NYHA functional class, a lower end diastolic pressure, and a higher ejection fraction compared with the rest of the group. The proportion of ventricular extrasystoles and ventricular tachycardias tended to be smaller in this subgroup, but the difference was not significant. Thus we concluded that in this subgroup only a negligible number of aberrant conducted beats might have been judged erroneously as ventricular extrasystoles or ventricular tachycardia.

Ventricular arrhythmias and digitalis treatment

To determine a possible arrhythmogenic effect of digitalis $^{14}$ in patients with idiopathic dilated cardiomyopathy the prevalence and severity of ventricular arrhythmias in patients treated and not treated with digitalis were compared (Table 3 ). Forty five patients received digoxin (mostly $\beta$-acetyldigoxin 0.3 
Table 2 Clinical, haemodynamic, and electrocardiographic findings in patients with $(A)$ and without $(B)$ atrial fibrillation. Figures are means $\pm S D$, unless otherwise stated

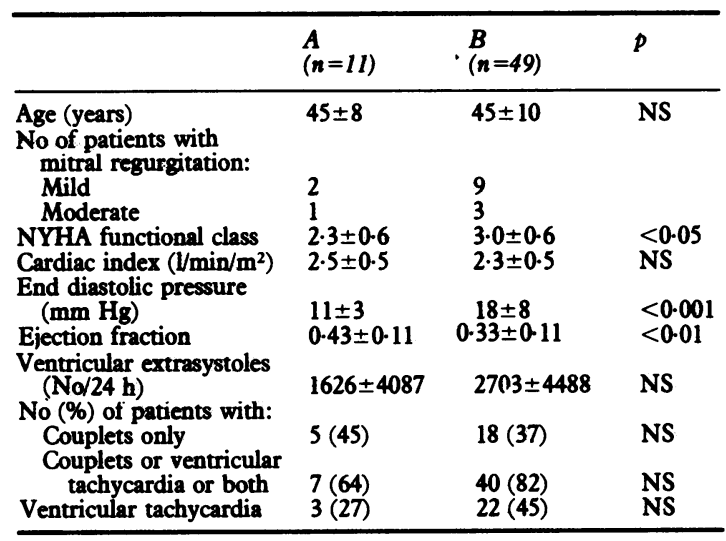

NS, not significant.
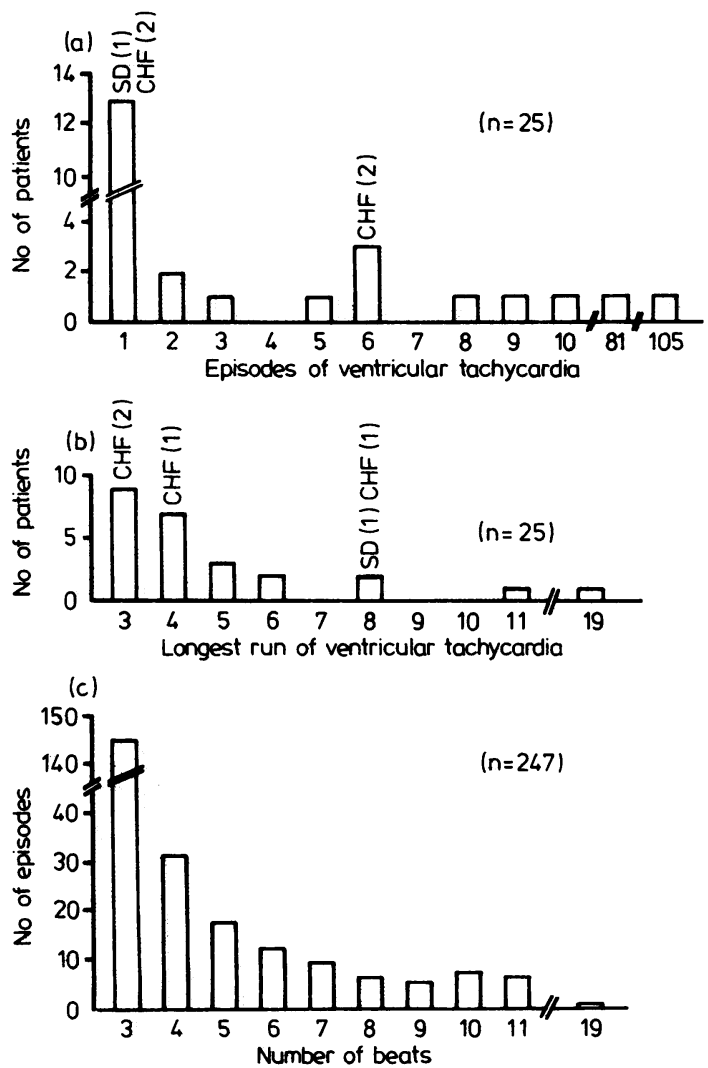

Fig. 2 (a) Number of episodes of ventricular tachycardia (median number 1.5) (the five patients with ventricular tachycardia who died of congestive heart failure (CHF) or sudden death (SD) are shown); (b) longest length of episodes of ventricular tachycardia for each patient (median 4 beats); and (c) number of episodes of ventricular tachycardia as a function of episode length (median length of all episodes 3 beats). $\mathrm{mg}$ or methyldigoxin $0.2 \mathrm{mg}$ per day) and four patients digitoxin $0.07-0.1 \mathrm{mg}$ per day. Eleven patients were treated with either diuretics or vasodilators alone or with both.

As shown in Table 3 there were no significant differences in clinical and haemodynamic indices for either group. Furthermore, the prevalence and severity of ventricular arrhythmias were similar. Thus no arrhythmogenic effect of digitalis could be established in our comparatively small study group.

\section{Ventricular arrhythmias and left ventricular function}

Patients with frequent ( $>1000$ ventricular extrasystoles $/ 24 \mathrm{~h} ; \mathrm{n}=25$ ) or infrequent $(<1000$ ventricular extrasystoles/24 $h ; n=35$ ) ventricular extrasystoles showed no significant difference with regard to age, NYHA functional class, cardiac index, end diastolic pressure, and ejection fraction (Table 4). In contrast, the mean values of NYHA functional class $(3 \cdot 3 . v 2 \cdot 6$; $\mathrm{p}<0.05)$, cardiac index $\left(2.2 v 2.7 \mathrm{l} / \mathrm{min} / \mathrm{m}^{2} ; \mathrm{p}<0.001\right)$, left ventricular end diastolic pressure $(21 v 14 \mathrm{~mm}$ $\mathrm{Hg} ; \mathrm{p}<0.002)$, and ejection fraction $(0.38 v 0.30$; $p<0.01$ ) were significantly different for patients with $(n=25)$ and without $(n=35)$ ventricular tachycardia. Fig. 3 shows the relation between the frequency of ventricular extrasystoles and ejection fraction and the relation between the grade of arrhythmia and ejection fraction. As Fig. $3 b$ shows there was a wide overlap in the ejection fraction of patients with and without ventricular tachycardia. Thus in patients with idiopathic

Table 3 Clinical, haemodynamic, and Holter electrocardiographic findings in patients with $(A)$ and without $(B)$ treatment with digitalis. Figures are means $\pm S D$, unless otherwise stated

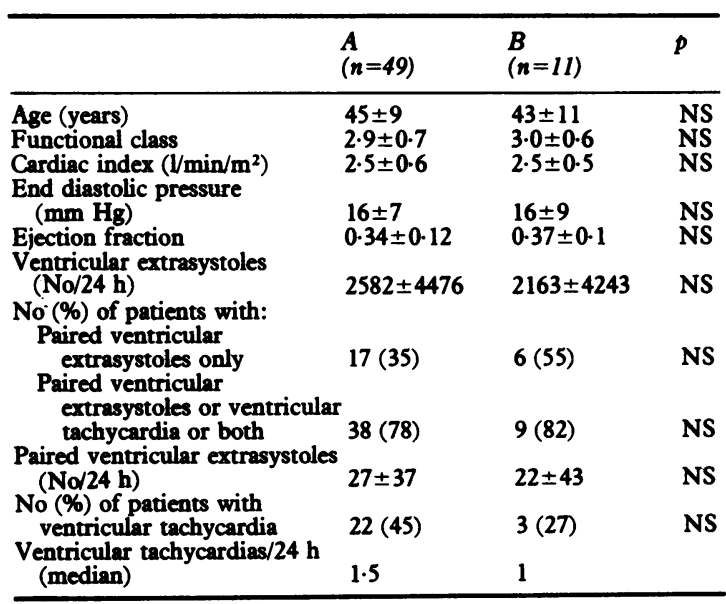

NS, not significant. 
dilated cardiomyopathy the correlation between ejection fraction and the occurrence of ventricular tachycardia was poor and hence of limited clinical value.

\section{Ventricular arrhythmias and survival}

During a follow up period of $12 \pm 5$ months seven patients died. All seven patients had sinus rhythm and an ejection fraction $<0.40$ (mean $0.25 \pm 0.07$ compared with $0.36 \pm 0.11$ for the 53 survivors $(p<0.02)$ ). Left ventricular end diastolic pressure was appreciably raised in these patients $(25 \pm 9 v 16 \pm 8 \mathrm{~mm}$ $\mathrm{Hg}, \mathrm{p}<0.01$ ). Thus patients who subsequently died could be identified by their severely impaired left ventricular function.

Three patients died suddenly-that is, within $<1$ hour of the onset of symptoms. Only one of these three patients had eight couplets and one ventricular tachycardia of eight beats on the ambulatory electrocardiogram (Fig. 2). The other two patients with sudden cardiac death had three and 18 couplets but no ventricular tachycardia. Four patients died of congestive heart failure. All four patients had ventricular tachycardia of three, four, or eight beats (Fig. 2). Patients who died of sudden cardiac death $(n=3)$ or of congestive heart failure $(n=4)$ could not be differenti-
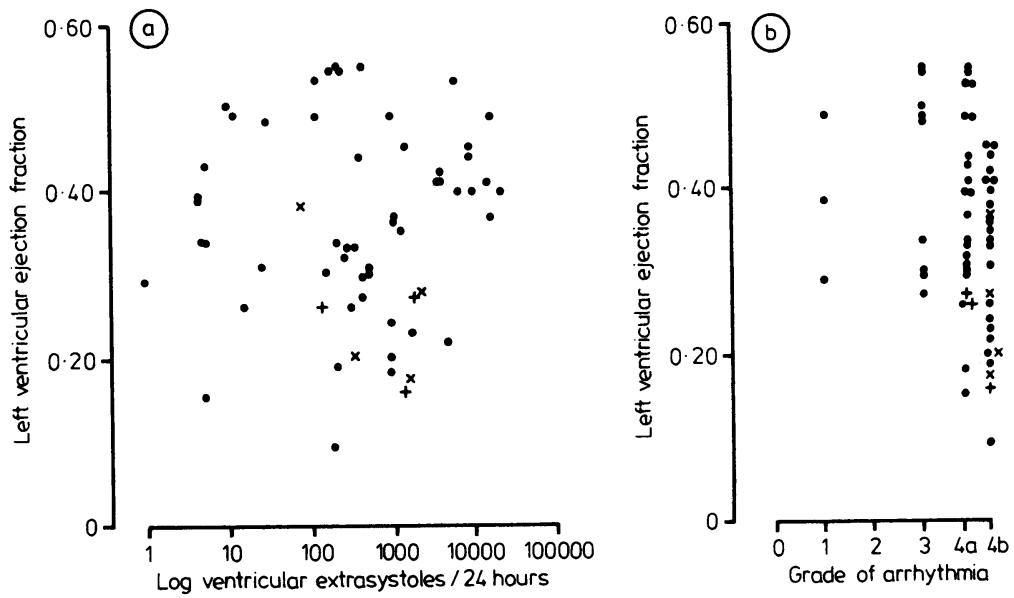

Fig. 3 (a) Relation between frequency of ventricular extrasystoles (logarithmic scale) and left ventricular ejection fraction. $(+)$-congestive heart failure (four patients); $(X)$-sudden death (three patients). (b) Relation between the highest grade of arrhythmia and left ventricular ejection fraction. $(+)$ and $(\times)$ as before.

Table 4 Clinical, haemodynamic, and Holter electrocardiographic findings in patients with frequent and infrequent ventricular extrasystoles and patients with and without ventricular tachycardia. Figures are means $\pm S D$, unless otherwise stated

\begin{tabular}{|c|c|c|c|c|c|c|}
\hline & \multicolumn{2}{|c|}{ With extrasystoles } & \multirow[t]{2}{*}{$p$} & \multicolumn{2}{|c|}{ Ventricular tachycardia } & \multirow[t]{2}{*}{$p$} \\
\hline & $\begin{array}{l}>1000 / 24 h \\
(n=25)\end{array}$ & $\begin{array}{l}<1000 / 24 h \\
(n=35)\end{array}$ & & $\begin{array}{l}\text { With } \\
(n=25)\end{array}$ & $\begin{array}{c}\text { Without } \\
(n=35)\end{array}$ & \\
\hline $\begin{array}{l}\text { Age (years) } \\
\text { No of patients with mitral regurgitation: } \\
\text { Mild } \\
\text { Moderate } \\
\text { Functional class } \\
\text { Cardiac index }\left(1 / \mathrm{min} / \mathrm{m}^{2}\right) \\
\text { End diastolic pressure }(\mathrm{mm} \mathrm{Hg}) \\
\text { Ejection fraction } \\
\text { Cardiothoracic ratio } \\
\text { Ventricular extrasystoles }(\mathrm{No} / 24 \mathrm{~h}) \\
\text { Paired ventricular extrasystoles }(\mathrm{No} / 24 \mathrm{~h}) \\
\text { No of sudden cardiac deaths } \\
\text { Total No of deaths }\end{array}$ & $\begin{array}{l}45 \pm 10 \\
5 \\
1 \\
3 \cdot 1 \pm 0 \cdot 6 \\
2 \cdot 4 \pm 0 \cdot 5 \\
17 \pm 8 \\
0 \cdot 35 \pm 0 \cdot 1 \\
0 \cdot 60 \pm 0 \cdot 11 \\
5676 \pm 5473 \\
40 \pm 43 \\
(n=25) \\
2 \\
4\end{array}$ & $\begin{array}{l}45 \pm 10 \\
6 \\
3 \\
2 \cdot 8 \pm 0 \cdot 7 \\
2 \cdot 5 \pm 0 \cdot 8 \\
16 \pm 8 \\
0 \cdot 35 \pm 0 \cdot 13 \\
0 \cdot 64 \pm 0 \cdot 11 \\
241 \pm 235 \\
11 \pm 25 \\
(n=22) \\
1 \\
3\end{array}$ & $\begin{array}{l}\text { NS } \\
\text { NS } \\
\text { NS } \\
\text { NS } \\
\text { NS }\end{array}$ & $\begin{array}{l}45 \pm 11 \\
5 \\
3 \\
3 \cdot 3 \pm 0 \cdot 6 \\
2 \cdot 2 \pm 0 \cdot 4 \\
21 \pm 8 \\
0 \cdot 30 \pm 0 \cdot 1 \\
0 \cdot 61 \pm 0 \cdot 11 \\
3305 \pm 4282 \\
41 \pm 45 \\
(n=24) \\
1 \\
5\end{array}$ & $\begin{array}{l}45 \pm 9 \\
6 \\
1 \\
2 \cdot 6 \pm 0 \cdot 5 \\
2 \cdot 7 \pm 0 \cdot 7 \\
14 \pm 7 \\
0 \cdot 38 \pm 0 \cdot 11 \\
0 \cdot 63 \pm 0 \cdot 12 \\
1934 \pm 4458 \\
12 \pm 22 \\
(n=23) \\
2 \\
2\end{array}$ & $\begin{array}{l}<0.05 \\
<0.001 \\
<0.002 \\
<0.01 \\
\text { NS } \\
\text { NS }\end{array}$ \\
\hline
\end{tabular}

NS, not significant. 
ated by the ejection fraction $(0.23 \pm 0.06 v 0.26 \pm 0.09)$, end diastolic pressure $(22 \pm 10 v 29 \pm 8 \mathrm{~mm} \mathrm{Hg})$, number of couplets (median $8 v 14 / 24$ hours), or number of ventricular extrasystoles $(1215 \pm 940 v$ $1160 \pm 1097 / 24$ hours). Thus ambulatory monitoring did not identify patients at increased risk of sudden cardiac death in our study.

\section{Discussion}

This study shows not only that ventricular arrhythmias occur frequently in patients with idiopathic dilated cardiomyopathy but also that these arrhythmias include a high percentage of high grade arrhythmias.

\section{FREQUENCY AND SEVERITY OF VENTRICULAR ARRHYTHMIAS}

All patients had ventricular extrasystoles, with $95 \%$ of the patients showing multiform ventricular extrasystoles and $80 \%$ repetitive ventricular extrasystoles. Forty two per cent of all patients had $>1000$ ventricular extrasystoles $/ 24 \mathrm{~h}$. There was a high prevalence of ventricular extrasystoles even in patients with moderately reduced ejection fractions $(0.41-$ 0.55 ). In this subgroup $40 \%$ of 21 patients had $>1000$ ventricular extrasystoles/24 $\mathrm{h}$ and $70 \%$ had repetitive ventricular extrasystoles.

The number and complexity of ventricular extrasystoles in idiopathic dilated cardiomyopathy seem to be higher than in any other cardiac disease reported so far. In patients with hypertrophic cardiomyopathy ventricular tachycardia was detected in $26 \%$ of 30 patients by 24 hour Holter monitoring by McKenna et $\mathrm{al}^{3}$ and in $19 \%$ of 100 patients by Savage et al. ${ }^{4}$ Multiform ventricular extrasystole were found in $69 \%$ by McKenna et $\mathrm{al}^{3}$ and in more than $50 \%$ by Savage et al.$^{4}$ In 430 patients with sustained myocardial infarction Bigger et al $^{15}$ reported a prevalence of ventricular tachycardia of $12 \%$. In the present study the prevalence was $42 \%$ in all patients, and $50 \%$ in the subgroup with an ejection fraction $<0.40$. Thus every second patient with clinically relevant idiopathic dilated cardiomyopathy had ventricular tachycardia on 24 hour Holter monitoring.

Our data are partly consistent with those of the retrospective study of Huang et al..$^{5}$ These workers reported a prevalence of multiform ventricular extrasystoles of $93 \%$ and of ventricular tachycardia of $60 \%$ in 35 patients with idiopathic dilated cardiomyopathy. In their study patients with atrial fibrillation ( $20 \%$ of 35 patients) were not evaluated separately. Furthermore, ventricular tachycardias with rates of $75 / \mathrm{min}$ or more were included, which is at variance with standard electrocardiographic nomenclature $^{16}$ and might include ventricular escape rhythms or delayed conduction or both. In our present study successive ventricular extrasystoles with a rate $<100 /$ min were not classified as ventricular tachycardia. These factors may be responsible for the considerably higher prevalence of ventricular tachycardias in the study of Huang et $a^{5}$ compared with our study $(60 \%$ $v 42 \%)$. In a preliminary report of 75 patients Meinertz et al found multiform ventricular extrasystoles in $85 \%$ and ventricular tachycardias consisting of three to 32 consecutive beats in $44 \%$ of patients. ${ }^{6}$ Thus the prevalence of $40 \%$ to $50 \%$ for ventricular tachycardias found in the present study seems to be a reasonable figure in patients with idiopathic dilated cardiomyopathy.

\section{VENTRICULAR ARRHYTHMIAS AND LEFT}

VENTRICULAR FUNCTION

Previous studies indicate that heart size and functional class at the time of diagnosis are indicators of prognosis. ${ }^{17}$ Furthermore it is known that in patients with coronary artery disease $e^{18} 19$ and aortic valve disease $^{20}$ the complexity of ventricular extrasystoles correlates with left ventricular function. If ventricular tachyarrhythmias really play a role in determining the prognosis of dilated cardiomyopathy it would be expected that the occurrence of complex ventricular arrhythmias would correlate with the degree of left ventricular impairment. It is surprising then that Huang $e t a l^{5}$ and Meinertz et $a l^{6}$ could not detect any relation between haemodynamic indices and the occurrence of ventricular tachyarrhythmias. In the present study, however, a highly significant (always $\mathrm{p}<0.01)$ difference in cardiac index, end diastolic pressure, and ejection fraction was found between patients with and without ventricular tachycardia. Despite this significant difference the correlation between ejection fraction and the grade of arrhythmia was poor in patients with idiopathic dilated cardiomyopathy compared with that in patients with coronary artery disease ${ }^{1819}$ or aortic valve disease. ${ }^{20}$ This poor correlation might be because all patients with idiopathic dilated cardiomyopathy have a ventricle which is already compromised-that is, the definition of idiopathic dilated cardiomyopathy necessarily includes a reduced ejection fraction-in contrast to patients with coronary artery disease or aortic valve disease, who may have either a normal or a reduced ejection fraction. The distribution of the grade of arrhythmia over a wider range of ejection fraction must, therefore, yield a better correlation between the grade of arrhythmias and haemodynamic indices.

PROGNOSTIC VALUE OF VENTRICULAR TACHYCARDIA

It is well known that heart size is an indicator of prognosis in patients with idiopathic dilated 
cardiomyopathy. ${ }^{17}$ Patients with subsequent sudden cardiac death may be identified by severely impaired left ventricular function. In this study, however, ambulatory monitoring failed to identify the very small group of three patients who subsequently died suddenly, since two of them showed only paired ventricular extrasystoles in their recordings. Since the prevalence of couplets and ventricular tachycardia is so high in patients with idiopathic dilated cardiomyopathy the mere presence of couplets and ventricular tachycardias cannot have a high predictive value. More refined approaches which take into account the number and rate of couplets and ventricular tachycardias in larger samples of patients are necessary to confirm the usefulness of ambulatory monitoring in these patients. In the study of Meinertz et $a l^{6}$ eight patients who died a sudden cardiac death had a mean of $32 \pm 12$ episodes of ventricular tachycardia and $81 \pm 30$ couplets $/ 24 \mathrm{~h}$. In contrast six patients who died of congestive heart failure had a mean of $1.2 \pm 0.7$ episodes of ventricular tachycardia and 0.5 couplets $/ 24 \mathrm{~h}$. Our data do not support these findings since only two of 60 patients had $>10$ episodes of ventricular tachycardia in 24 hours (Fig. 2) and only five had $>80$ paired ventricular extrasystoles $/ 24 \mathrm{~h}$. None of these patients died a sudden cardiac death during the follow up period.

Thus our data show that it is more reliable to identify patients with idiopathic dilated cardiomyopathy at risk of sudden cardiac death by their severely impaired ventricular function and not by the result of 24 hour ambulatory monitoring.

We thank S Gund for her technical assistance.

This work was supported by the Deutsche Forschungsgemeinschaft within the SFB 90, Kardiovaskuläres System, University of Heidelberg.

\section{References}

1 Kuhn H, Loogen F. Erkrankungen des Myokards. In: Kübler W, Krayenbühl H, eds. Kardiologie in Klinik und Praxis. Stuttgart, New York: Thieme, 1981: 48.1-43.

2 Johnson RA, Palacios I. Dilated cardiomyopathies of the adult. Part 1. N Engl F Med 1982; 307, 1051-8.

3 McKenna WJ, Chetty S, Oakley CM, Goodwin JF. Arrhythmia in hypertrophic cardiomyopathy: exercise and 48 hour ambulatory electrocardiographic assessment with and without beta adrenergic blocking therapy. $A m \mathcal{F}$ Cardiol 1980; 45: 1-5.

4 Savage DD, Seides SF, Maron BJ, Myers DJ, Epstein SE.
Prevalence of arrhythmias during 24-hour electrocardiographic monitoring and exercise testing in patients with obstructive and nonobstructive hypertrophic cardiomyopathy. Circulation 1979; 59: 866-75.

5 Huang SK, Messer JV, Denes P. Significance of ventricular tachycardia in idiopathic dilated cardiomyopathy: observations in 35 patients. Am $\mathcal{f}$ Cardiol 1983; 51: 507-12.

6 Meinertz W, Kasper T, Hofmann T, et al. Prevalence and prognostic significance of ventricular arrhythmias in congestive cardiomyopathy [Abstract]. Circulation 1982; 66 (suppl II): 117.

7 Fuster V, Gersh BJ, Giuliani ER, Tajik AJ, Brandenburg RO, Frye RL. The natural history of idiopathic dilated cardiomyopathy. Am f Cardiol 1981; 47: 525-31.

8 Goodwin JF, Oakley CM. The cardiomyopathies. $\mathrm{Br}$ Heart F 1972; 34: 545-52.

9 The Criteria Committee of the New York Heart Association. Nomenclature and criteria for diagnosis of diseases of the heart and great vessels. 8th ed. Boston: Little, Brown, 1979: 290.

10 Olshausen Kv, Leitl C, Kübler W. Computer assisted data analysis for the "Pathfinder" ambulatory ECG system. Biomed Tech (Berlin) 1982; 27 : 272-9.

11 Ryan M, Lown B, Horn H. Comparison of ventricular ectopic activity during 24-hour monitoring and exercise testing in patients with coronary heart disease. $N \mathrm{Englf}$ Med 1975; 292: 224-9.

12 Sachs L. Angewandte Statistik. 5th ed. Berlin, Heidelberg, New York: Springer, 1978.

13 Kennedy HL. Ambulatory electrocardiography. Philadelphia: Lea and Febinger, 1981: 132-6.

14 Moss AJ, Davis HT, Conard DL, De Camilla JJ, Odoroff CL. Digitalis-associated cardiac mortality after myocardial infarction. Circulation 1981; 64: 1150-6.

15 Bigger JT Jr, Weld FM, Rolnitzky LM. Prevalence, characteristics and significance of ventricular tachycardia (three or more complexes) detected with ambulatory electrocardiographic recording in the late hospital phase of acute myocardial infarction. Am $\mathcal{F}$ Cardiol 1981; 48: 815-23.

16 WHO/ISC Task Force. Definition of terms related to cardiac rhythm. Am Heart f 1978; 95: 796-806.

17 Segal JP, Stapleton JF, McClellan JR, Waller BF, Harvey WP. Idiopathic cardiomyopathy: clinical features, prognosis and therapy. Curr Probl Cardiol 1978; 3: 1-49.

18 Califf RM, McKinnis RA, Burks J, et al. Prognostic implications of ventricular arrhythmias during 24 hour ambulatory monitoring in patients undergoing cardiac catheterization for coronary artery disease. $A m \mathcal{F}$ Cardiol 1982; 50: 23-31.

19 Schulze RA Jr, Strauss HW, Pitt B. Sudden death in the year following myocardial infarction: relation to ventricular premature contractions in the late hospital phase and left ventricular ejection fraction. Am $\mathcal{F}$ Med 1977; 62: 192-9.

20 Olshausen Kv, Schwarz F, Apfelbach J, Röhrig N, Krämer B, Kübler W. Determinants of the incidence and severity of ventricular arrhythmias in aortic valve disease. Am f Cardiol 1983; 51: 1103-9. 